\title{
Physical and chemical properties of roselle extract nanocapsule with inulin, chitosan and maltodextrin as encapsulant
}

\author{
1,*Yudhistira, B. and ${ }^{2}$ Choiriyah, N.A. \\ ${ }^{1}$ Food Science and Technology, Faculty of Agriculture, Sebelas Maret University, Surakarta \\ ${ }^{2}$ Department of Culinary arts, Akademi Kuliner dan Patiseri OTTIMMO Internasional, Surabaya
}

\section{Article history:}

Received: 30 January 2021

Received in revised form: 14

March 2021

Accepted: 16 May 2021

Available Online: 12

December 2021

Keywords:

Chitosan,

Inulin,

Maltodextrin,

Nanoencapsulation,

Roselle

DOI:

https://doi.org/10.26656/fr.2017.5(6).071

\begin{abstract}
Roselle contains high phenolic compounds, mainly anthocyanins that are not stable with $\mathrm{pH}$, metal ions, light exposure, temperature, oxygen, and enzymatic activity. The stability of phenolic compounds can be improved by nanoencapsulation. This research was aimed to evaluate the effect of inulin, inulin-chitosan and inulin-chitosan-maltodextrin with varying concentrations as encapsulants towards the physicochemical properties and encapsulation efficiency of nanocapsules product by spray drying. Roselle extract nanocapsules were prepared using various types and concentrations of encapsulants (inulin, inulin-chitosan and inulin-chitosan-maltodextrin). The solubility of nanocapsules ranged from $69.31-83.2 \%$, while the hygroscopicity of nanocapsules was varied, approximately $17.89-23.79 \%$. Nanocapsules moisture content was approximately 2.83 $4.27 \%$, while the total phenolic content of nanocapsules ranged from $6.74-13.41 \mathrm{mg}$ GAE/g DW. The total anthocyanin of roselle extract nanocapsules was approximately $2.25-4.82 \mathrm{mg} / \mathrm{g}$ DW. The encapsulation efficiency of phenolic compounds in this study were approximately $60.31-77.13 \%$. Nanocapsules with inulin-chitosan-maltodextrin (2.4\%-2.4\%-0.2\%) had good properties of nanocapsules such as good solubility, high total phenolic content and total anthocyanin content. Nanocapsules with $5 \%$ inulin and inulinchitosan-maltodextrin $(2.4 \%-2.4 \%-0.2 \%)$ had particle size of 641.4 and $411.1 \mathrm{~nm}$ respectively. The nanocapsules had a spherical shape, smooth surfaces but also a few had indentations.
\end{abstract}

\section{Introduction}

Roselle contains high phenolic compounds, mainly anthocyanins that are known responsible for the red colour. Phenolic and anthocyanin are compounds that are not stable with $\mathrm{pH}$, metal ions, light exposure, temperature, oxygen, and enzymatic activity (Bakowska et al., 2003). Stability is an important aspect of the use of phenolic compounds as anti-oxidants and colorants in food. The stability of phenolic compounds can be improved by using spray drying technology for nanoencapsulation (Ersus and Yurdagel, 2007).

Nanoencapsulation is one innovation in technology by means of encapsulating the active compound in an encapsulant at a very small size on the nanometer scale $(0-1000 \mathrm{~nm})$ (Carvajal-Zarrabal et al., 2009). Carbohydrates are widely used at nanoencapsulation, but research on inulin as encapsulant is still limited. The morphology of microcapsule with inulin as encapsulant has a smooth surface without cracks (Saenz et al., 2013).
Sun-Waterhouse et al. (2013) also reported that microencapsulation with inulin has high encapsulation efficiency. Unfortunately, inulin's particle sizes are large, adhesive, and hygroscopic which limit its use as an encapsulant.

To produce particle size in nanoscale at roselle's extract encapsulation, the presence of inulin can be replaced in part by chitosan. In some studies, forming nanoparticles can be generated through an electrostatic crosslink between the amino group of the positively charged chitosan with negatively charged sodium tripolyphosphate (STPP) (Bahreini et al., 2014). Chitosan also has hygroscopic properties like inulin. To minimize the sticky and hygroscopic properties of nanocapsules, the use of inulin can be replaced in part by maltodextrin. Cai and Croke (2000) and Saénz et al. (2009), state that maltodextrin as an encapsulant has been used widely in the food industry because it has low hygroscopicity and high solubility. This research was aimed to evaluate the effect of inulin and inulin-chitosan 
and inulin-chitosan-maltodextrin with varying concentrations as encapsulants towards the physicochemical properties and encapsulation efficiency of nanocapsules product by spray drying.

\section{Materials and methods}

\subsection{Materials}

Dry roselle (Hibiscus sabdariffa) petals were obtained from a local farmer in Tawangmangu, Karanganyar, Indonesia.

\subsection{Roselle extraction}

Dry roselle (Hibiscus sabdariffa) petals were obtained from a local farmer in Tawangmangu, Karanganyar, Indonesia. Dry roselle petals were powdered using a chopper. Powdered dried roselle petals were mixed with ethanol $35 \%$ and citric acid then macerated for $24 \mathrm{hrs}$ at room temperature. The ratio between powdered dried roselle petals, the solvent, and citric acid were 1:10:0.2 (w/v/w). The separation was carried out in vacuum filtration to obtain the supernatant. The roselle extract was obtained by evaporating the supernatant by using a rotary evaporator at $45^{\circ} \mathrm{C}$. The extract was then stored in screw-capped inert bottle until the experiment.

\subsection{Nanocapsules preparation}

The encapsulants were used in the spray drying process. The encapsulants were inulin with the brand Orafti with DP $>10$ purchased from Orafti sales office in Indonesia, chitosan with deacetylation percent of $96.33 \%$ and maltodextrin DE 10 were purchased from SigmaAldrich, US. Nanocapsules preparation in this study applied Saloko et al. (2013) method with some modification. Chitosan $(0.2 \% \mathrm{w} / \mathrm{w})$ and $15 \%$ roselle extract $(\mathrm{w} / \mathrm{w})$ were dissolved in water then heated until $40^{\circ} \mathrm{C}$ for $15 \mathrm{mins}$. Then, STPP $(0.04 \% \mathrm{w} / \mathrm{w})$ was mixed with chitosan solution using a magnetic stirrer for 20 mins. Afterwards, inulin $(4.8 \% ; 9.8 \% ; 14 \% ; 8 \%(\mathrm{w} / \mathrm{w}))$ or inulin-maltodextrin $(2.4 \%-2.4 \% ; 4.9 \%-4.9 \% ; 7.4 \%$ $7.4 \%(\mathrm{w} / \mathrm{w}))$ were dissolved completely in chitosanSTPP-roselle extract solution until became dispersion. The dispersion was homogenized using a rotor-stator homogenizer (Ultraturrax T50 Basic IKA Werke, Germany) at $6.400 \mathrm{rpm}$ for 5 mins. The Spray drying process was performed at a temperature inlet of $120^{\circ} \mathrm{C}$ and a flow rate of $5 \mathrm{~mL} / \mathrm{min}$.

For nanocapsules made from inulin alone, inulin $(5 \%, 10 \%$, and $15 \%)$ were mixed with roselle extract $(15 \%)$ and water using a magnetic stirrer for 5 mins. Then, the solution was mixed with STPP $(0.04 \%)$ using a magnetic stirrer for 20 mins. Afterwards, the solution was homogenized and spray dried using the same treatment as the other samples. The types of the encapsulant, the concentration of encapsulant and the sample codes are shown in Table 1. The nanocapsules were characterized for solubility, hygroscopicity, anthocyanins content, phenolic compounds, antioxidant activity, microstructure, and size. All analyses were performed in triplicate and the absence of light.

Table 1. The type and concentration of encapsulants used for roselle extract nanoencapsulation and the sample codes used for this study.

\begin{tabular}{lc}
\hline Type and concentration of Encapsulant & Sample \\
\hline Inulin (5\%) & $\mathrm{S} 1$ \\
Inulin-Chitosan (4.8\%-0.2\%) & $\mathrm{S} 2$ \\
Inulin-Chitosan-Maltodextrin $(2.4 \%-2.4 \%-0.2 \%)$ & $\mathrm{S} 3$ \\
Inulin (10\%) & $\mathrm{S} 4$ \\
Inulin-Chitosan (9.8\%-0.2\%) & $\mathrm{S} 5$ \\
Inulin-Chitosan-Maltodextrin (4.9\%-4.9\%-0.2\%) & $\mathrm{S} 6$ \\
Inulin (15\%) & $\mathrm{S} 7$ \\
Inulin-Chitosan (14.8\%-0.2\%) & $\mathrm{S} 8$ \\
Inulin-Chitosan-Maltodextrin (7.4\%-7.4\%-0.2\%) & $\mathrm{S} 9$ \\
\hline
\end{tabular}

\subsection{Analysis}

\subsubsection{Determination of moisture content}

The moisture contents of the nanocapsules were analysed using the gravimetric method.

\subsubsection{Determination of solubility}

Solubility was analysed according to the study by Braga et al. (2019) with some adaptations, where $0.5 \mathrm{~g}$ of the nanocapsule was placed in beakers containing 50 $\mathrm{mL}$ of distilled water then homogenized for thirty mins at $100 \mathrm{rpm}$ at room temperature. The nanocapsule solution was then centrifuged for five mins at $3500 \mathrm{rpm}$. The supernatant was transferred to a porcelain dish of known weight and kept in the oven (Memmert) at $105^{\circ} \mathrm{C}$ until the mass remained constant.

\subsubsection{Determination of hygroscopicity}

The methodology proposed by Braga et al. (2019) with some modifications was employed. As much as 0.2 $\mathrm{g}$ of the nanocapsule was placed in porcelain capsules, then stored in a desiccator containing sodium chloride (saturated solution) for seven days at room temperature. The result was expressed in percentage (\%).

\subsubsection{Determination of total phenolics}

The phenolic content in the nanocapsules was determined by employing the Folin-Ciocalteu method, according to the protocol described by González et al. (2019) with modifications. In this procedure, $0.5 \mathrm{~g}$ of nanocapsule was resuspended in $20 \mathrm{~mL}$ of distilled 
water. Then, $1 \mathrm{~mL}$ of nanocapsule solution was mixed with $10 \mathrm{~mL}$ of distilled water and $500 \mu \mathrm{L}$ of FolinCiocalteu reagent and was allowed to react for 3 mins. Then, $1.5 \mathrm{~mL}$ of sodium carbonate $(20 \%$, w/v) were added and allowed to stand for 1 hour. The reading was performed in a UV-visible spectrophotometer (Shimadzu $-1800)$ at $765 \mathrm{~nm}$, using distilled water as blank. The results were expressed in $\mathrm{mg}$ gallic acid equivalent per $\mathrm{g}$ dry weight sample (mg GAE/g DW).

\subsubsection{Determination of anthocyanins}

The total anthocyanin content was determined by the $\mathrm{pH}$ differential (Yousefi et al., 2015) method, where 0.1 $\mathrm{g}$ of nanocapsule was added with $10 \mathrm{~mL}$ of distilled water. Then the solution was dissolved in $\mathrm{KCl}$ buffer (0.025 M, pH 1.0) and $\mathrm{CH} 3 \mathrm{COONa}(0.4 \mathrm{M}, \mathrm{pH} 4.5)$ at a ratio of 1:7.5. The absorbance (A) was measured in UVvisible (Shimadzu-1800) spectrophotometer at 510 and $700 \mathrm{~nm}$

\subsubsection{Determination of encapsulation efficiency}

Determination of encapsulation efficiency (EE) of phenolic compound (PC) using the method by González et al. (2019). EE of PC was calculated according to Equation 1.

$$
E E \%=\frac{\text { Total PC content }- \text { Surface PC content }}{\text { Total PC Content }} \times 100
$$

For the evaluation of the total PC content, $100 \mathrm{mg}$ of nanocapsule was resuspended in $1 \mathrm{~mL}$ of deionized water. The sample was placed in a sonication bath for 30 min at $28^{\circ} \mathrm{C}$ to allow the rupture of the nanocapsules in the solution. $95 \%$ ethanol $(10 \mathrm{~mL})$ was added and the solution was left in agitation for $30 \mathrm{~min}$. The sample was centrifuged at $4500 \mathrm{~g}$ for 10 mins and then filtered at $0.45 \mu \mathrm{m}$. The determination of the phenolic content was performed by Folin-Ciocalteau.

\subsubsection{Particle size measurement of nanocapsules}

The measurement of particle size was done by suspending the nanocapsules in distilled water. The particle sizes were measured using a laser particle size distribution analyser (Malvern Zetasizer Nanoseries Nano ZS Ver 6.20, Malvern Instruments Ltd., Malvern, UK). The size distribution was determined by the span value (Saloko et al., 2014). The measurements were carried out triplicate.

\subsubsection{Observation of nanocapsules morphology}

The morphology of the nanocapsules obtained under optimal conditions was evaluated by scanning electron microscopy (SEM). The nanocapsules were coated with gold using a Varian Vacuum Evaporator PS 10E and analysed using a LEO 1420 VP (LEO Electron
Microscopy Ltd., UK), operated at $20 \mathrm{kV}$. The images were digitally obtained using software (EDS 7424, Oxford Instruments, UK).

\subsubsection{Statistical analysis}

The analysis data obtained were analysed statistically using the one-way ANOVA SPSS 16.0 method. If it shows significant results then proceed with a real difference test using Duncan's Multiple Range Test (DMRT) at the significance level $\alpha=0.05$.

\section{Results and discussion}

\subsection{Physical characterization of nanocapsules}

The physical characterizations of nanocapsules are summarized in Table 2. As observed in Table 2, the solubility of nanocapsules were approximately 69.31 $83.2 \%$. S1 had the lowest solubility because inulin structures have a long chain. S4 and S7 showed better solubility (S1). The greater use of inulin encapsulant concentration can increase solubility. It is associated with the high total solids that affect forming crust. The hygroscopicity of nanocapsules were approximately $17.89-23.79 \%$ (Table 2.). The changing of inulin encapsulant with maltodextrin can cause a decrease in hygroscopicity. Maltodextrin has fewer hydrophilic compounds than inulin. According to Saenz et al. (2009), maltodextrin is an encapsulant that has low hygroscopicity. S2 had the highest hygroscopicity.

\subsection{Chemical characterization of nanocapsules and encapsulation efficiency}

The chemical characterization of nanocapsules and encapsulation efficiency were summarized in Table 2 . Nanocapsules had a moisture content were approximately $2.83-4.27 \%$. S8 and S9 had a lower moisture content compared to S2 and S3. Bhusari et al. (2014) report that the addition of encapsulant concentration can increase the total soluble solid and decrease the moisture content in the nanoparticle solution. The moisture content of the nanocapsules in this study was in accordance with the research by SilvaIbrahim et al. (2013) and De Souza et al. (2015). The moisture content of jabuticaba microcapsules and bordo grape microcapsules were approximately 2.11-5.31\% (Silva-Ibrahim et al., 2013) and 2.96-4.94\% (De Souza et al., 2015), respectively.

The yield of inulin is higher than Arfiani (2016) which has the highest white sweet potato yield of 5.5\% and $22.53 \%$ for blanching white sweet potato inulin with 2\% egg albumin treatment (Yudhistira et al., 2020). Inulin recovery with foam mat drying method was higher than inulin by oven drying method. Extraction Inulin 
Table 2. Physical and chemical characterization of roselle extract nanocapsules

\begin{tabular}{ccccccc}
\hline Sample & $\begin{array}{c}\text { Solubility } \\
(\%)\end{array}$ & $\begin{array}{c}\text { Hygroscopicity } \\
(\%)\end{array}$ & $\begin{array}{c}\text { Moisture } \\
\text { content } \\
(\%)\end{array}$ & $\begin{array}{c}\text { Total phenolic } \\
\text { content } \\
(\text { mg GAE/g DW })\end{array}$ & $\begin{array}{c}\text { Anthocyanin } \\
\text { content } \\
(\mathrm{mg} / \mathrm{g} \mathrm{DW})\end{array}$ & $\begin{array}{c}\text { Encapsulation } \\
\text { efficiency } \\
(\%)\end{array}$ \\
\hline S1 & $69.31^{\mathrm{a}}$ & $20.99^{\mathrm{b}}$ & $3.06^{\mathrm{a}}$ & $11.76^{\mathrm{e}}$ & $4.48^{\mathrm{c}}$ & $62.39^{\mathrm{a}}$ \\
S2 & $79.19^{\mathrm{bcd}}$ & $23.79^{\mathrm{c}}$ & $4.27^{\mathrm{c}}$ & $13.41^{\mathrm{f}}$ & $4.82^{\mathrm{d}}$ & $60.31^{\mathrm{a}}$ \\
S3 & $83.2^{\mathrm{d}}$ & $22.03^{\mathrm{b}}$ & $3.88^{\mathrm{bc}}$ & $13.25^{\mathrm{f}}$ & $4.76^{\mathrm{d}}$ & $72.42^{\mathrm{c}}$ \\
S4 & $76.4^{\mathrm{b}}$ & $20.3^{\mathrm{b}}$ & $2.91^{\mathrm{a}}$ & $7.86^{\mathrm{bc}}$ & $3.06^{\mathrm{b}}$ & $62.17^{\mathrm{a}}$ \\
S5 & $77.71^{\mathrm{bc}}$ & $21.33^{\mathrm{b}}$ & $3.27^{\mathrm{ab}}$ & $8.79^{\mathrm{d}}$ & $2.97^{\mathrm{b}}$ & $67.78^{\mathrm{b}}$ \\
S6 & $81.91^{\mathrm{cd}}$ & $17.89^{\mathrm{a}}$ & $3.41^{\mathrm{ab}}$ & $8.68^{\mathrm{cd}}$ & $3.03^{\mathrm{b}}$ & $72.50^{\mathrm{c}}$ \\
S7 & $79.36^{\mathrm{bcd}}$ & $20.57^{\mathrm{b}}$ & $2.83^{\mathrm{a}}$ & $6.80^{\mathrm{a}}$ & $2.30^{\mathrm{a}}$ & $65.58^{\mathrm{b}}$ \\
S8 & $81.91^{\mathrm{cd}}$ & $20.81^{\mathrm{b}}$ & $2.81^{\mathrm{a}}$ & $6.74^{\mathrm{a}}$ & $2.25^{\mathrm{a}}$ & $65.98^{\mathrm{b}}$ \\
S9 & $82.56^{\mathrm{cd}}$ & $18.11^{\mathrm{a}}$ & $2.92^{\mathrm{a}}$ & $7.06^{\mathrm{ab}}$ & $2.32^{\mathrm{a}}$ & $77.13^{\mathrm{d}}$ \\
\hline
\end{tabular}

Values are presented as means. Values with the different superscript within the column are significantly different at $\mathrm{p} \leq 0.05$.

from white sweet potato reported by Yudhistira, Suswanti and Luwidharto (2020), the best yield is $7.72 \%$ from the solvent ratio of $1: 2$ for $12 \mathrm{hrs}$ treatment. The total phenolic content of nanocapsules was approximately $6.74-13.41 \mathrm{mg}$ GAE/g DW. Total anthocyanin of extract roselle nanocapsules was approximately 2.25-4.82 mg/g DW (Table 2). S1 had the lower total phenolic and total anthocyanin content compared to S2 and S6. Inulin was less strong in protecting phenolic and anthocyanin compounds. The replacement of inulin with chitosan both chitosanmaltodextrin can improve the properties of inulin in protecting phenolic and anthocyanin compounds. A study reported that inulin was less effective than maltodextrin in polyphenol encapsulation from blackcurrant (Bakowska et al., 2003) also from cactus pear (Saenz et al., 2009). According to Robert et al., (2012), each encapsulant had different optimum parameters in the spray drying process due to the different properties of each encapsulant such as solubility and viscosity which affect the formation rate of crust on the surface of the particle. This study showed that the addition of encapsulant concentrations affected the decrease in total phenolic and anthocyanin contents. Gutierrez et al. (2014) also found the same phenomenon. This was associated with an increase in the total soluble solids from encapsulants. EE of PC in this study were approximately $60.31-77.13 \%$. A previous study by Robert et al. (2012) shows EE of PC in spray drying process using inulin of $67.5 \%-96.4 \%$, while in González et al. (2019), EE of PC in spray drying process using sodium alginate of $57-68 \%$.

In this study, the EE of PC was strongly influenced by the type of encapsulation used. EE of PC produced using inulin alone was lower than EE of PC using inulinchitosan also inulin-chitosan-maltodextrin. This showed the interaction between inulin and PC was less good when compared to the interaction between Inulinchitosan and PC also inulin-maltodextrin-chitosan and PC. In the use of chitosan-inulin or chitosan-inulin- maltodextrin for nanoencapsulation, phenolic compounds were trapped in chitosan first then inulin or inulin-maltodextrin would coat the chitosan particles and phenolic compounds of roselle extract. Whereas, in the use of inulin encapsulation without combination with other encapsulants, phenolic compounds were trapped by inulin.

The use of chitosan encapsulants resulted in better interactions with phenolic compounds due to electrostatic bonds, hydrogen bonds, and ester bonds. In acidic conditions, gallic acid compounds (one of the phenolic compounds in roselle) were not dissociated, form ester bonds when reacted with $\mathrm{CH} 2 \mathrm{OH}$ from chitosan, whereas when gallic acid were dissociated, COO- of gallic acid would occur electrostatic reaction with the group $\mathrm{NH}^{3+}$ of chitosan causing electrostatic bonds (Silva-Weiss et al., 2013). Palma et al. (2014) reported that the interaction between inulin and phenolic compounds through hydrogen bonds.

EE of PC using inulin was low, this also related to the low solubility of inulin. According to Tonon et al. (2010), encapsulants with low solubility is caused when bioactive compounds do not diffuse properly into particles leading to phenolic compounds accumulating outside the surface layer of nanocapsules after the spray drying process. Table 2. shows that the increase of encapsulant concentration (inulin alone, inulin-chitosan, inulin-chitosan-maltodextrin) can increase encapsulation efficiency. Based on Robert et al. (2012), increasing the encapsulant concentration would increase the efficiency of encapsulation because the increase in total soluble solids would affect the viscosity and solubility which would affect the formation rate of crust on the particle surface. According to Gharsallaoui et al. (2007), the high formation of dry outer layers causes water diffusion but still can maintain bioactive compounds.

\subsection{Particle size of nanocapsules}

Observation of particle size distribution was carried 
out on selected products. The selected product was S3. This selection was based on the best properties of nanocapsules like good solubility, high total phenolic content, total anthocyanin content and encapsulation efficiency. Then S3 was compared with nanocapsules produced from inulin alone (S1) to determine the ability of inulin to produce nano-sized nanocapsules. The particle size distribution of nanocapsules is shown in Table 3. S1 and S3 had a particle size of $641.4 \mathrm{~nm}$ and $411.1 \mathrm{~nm}$ respectively, where $\mathrm{S} 3$ had a smaller size than S1. In the nanoparticle solution of S3 occurred high level crosslinking between chitosan and STPP. The presence of chitosan and STPP would produce an ionic reaction due to the interaction of the positive electron of the chitosan amino group and the STPP negative electron. Azevedo et al. (2014), report that the presence of strong ionic reactions contributes to the reduction in particle size. The polydispersity index of S1 and S3 were 0.281 and 0.647. S3 had a heterogeneous size. Gharsallaoui et al. (2007), reported that high viscosity can cause particles to have heterogeneous sizes.

Table 3. Particle size of nanocapsules

\begin{tabular}{ccc}
\hline Sample & Diameter $(\mathrm{nm})$ & Polydispersity index \\
\hline S1 & 641.4 & 0.281 \\
S3 & 411.1 & 0.647 \\
\hline
\end{tabular}

\subsection{Nanocapsules morphology}

Observation of the nanocapsules morphology was analysed using Scanning Electron Microscopy (SEM) to know the texture, shape and surface of the nanocapsules. The morphology of the nanocapsules is shown in Figure 1. S3 had a spherical shape. Some of them had smooth surfaces, but also a few had indentations. Nanocapsules had no cracks which indicated that the crust formed is resistant to heat. The shrinkage forms due to the inlet spray drying temperature used being too low. Saénz et al. (2009) and Tonon et al. (2009), state that the particles contained in indentations are obtained through the spray drying process due to shrinking particles. Nanocapsules shrinkage was due to drastic water loss followed by cooling. Cai and Croke (2000), reported that low spray drying temperatures cause the nanocapsules to shrink until indentation occurs. The use of low inlet temperatures causes the diffusion of water particles to be slower so that the particles have more time to shrink.

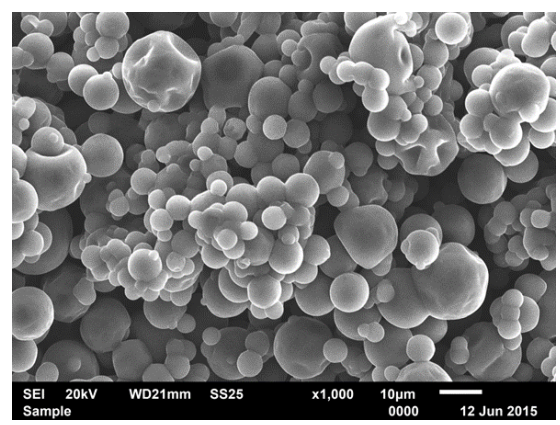

Figure 1. Nanocapsules morphology of S3
Figure 1 shows that many nanocapsules undergo agglomeration. This is due to the hygroscopic properties. Hygroscopic nanocapsules properties are associated with the use of inulin and chitosan. The presence of hydrophilic groups in inulin and chitosan encapsulants causes high hydrogen bonds between particles.

\section{Conflict of interest}

The authors declare no conflict of interest.

\section{References}

Azevedo, M.A., Bourbon, A.I., Vicente, A.A. and Cerqueira, M.A. (2014). Alginate/chitosan nanoparticles for encapsulation and controlled release of vitamin B2. International Journal of Biological Macromolecules, 71, 141-146. https:// doi.org/10.1016/j.ijbiomac.2014.05.036

Bahreini, E., Aghaiypour, K., Abbasalipourkabir, R., Mokarram, A.R., Goodarzi, M.T. and Saidijam, M. (2014). Preparation and nanoencapsulation of 1asparaginase II in chitosan-tripolyphosphate nanoparticles and in vitro release study. Nanoscale Research Letters, 9(1), 1-13. https:// doi.org/10.1186/1556-276x-9-340

Bakowska, A., Kucharska, A.Z. and Oszmiański, J. (2003). The effects of heating, UV irradiation, and storage on stability of the anthocyanin-polyphenol copigment complex. Food Chemistry, 81(3), 349355. https://doi.org/10.1016/s0308-8146(02)00429-6

Bhusari, S.N., Muzaffar, K. and Kumar, P. (2014). Effect of carrier agents on physical and microstructural properties of spray dried tamarind pulp powder. Powder Technology, 266, 354-364. https:// doi.org/10.1016/j.powtec.2014.06.038

Braga, A.B.A.C., Costa, C.J.M., Pomella, A.W.V., Ribeiro, E.J., Santos, L.D. and Zotarelli, M.F. (2019). Evaluation of lethality temperature and use of different wall materials in the microencapsulation process of Trichoderma asperellum conidias by spray drying. Powder Technology, 347, 199-206. https://doi.org/10.1016/j.powtec.2019.02.037

Cai, Y.Z. and Croke, H. (2000). Production and Properties of Spray-dried. Journal of Food Science, $65,1248-1252$.

Carvajal-Zarrabal, O., Hayward-Jones, P.M., OrtaFlores, Z., Nolasco-Hipólito, C., Barradas-Dermitz, D.M., Aguilar-Uscanga, M.G. and PedrozaHernández, M.F. (2009). Effect of Hibiscus sabdariffa L. dried calyx ethanol extract on fat absorption-excretion, and body weight implication in rats. Journal of Biomedicine and Biotechnology, 2009, 394592. https://doi.org/10.1155/2009/394592 
De Souza, V.B., Thomazini, M., Balieiro, J.C.D.C. and Fávaro-Trindade, C.S. (2015). Effect of spray drying on the physicochemical properties and color stability of the powdered pigment obtained from vinification byproducts of the Bordo grape (Vitis labrusca). Food and Bioproducts Processing, 93, 39-50. https:// doi.org/10.1016/j.fbp.2013.11.001

Ersus, S. and Yurdagel, U. (2007). Microencapsulation of anthocyanin pigments of black carrot (Daucus carota L.) by spray drier. Journal of Food Engineering, 80(3), 805-812. https:// doi.org/10.1016/j.jfoodeng.2006.07.009

Gharsallaoui, A., Roudaut, G., Chambin, O., Voilley, A. and Saurel, R. (2007). Applications of spray-drying in microencapsulation of food ingredients: An overview. Food Research International, 40(9), 1107 -1121. https://doi.org/10.1016/j.foodres.2007.07.004

González, E., Gómez-Caravaca, A.M., Giménez, B., Cebrián, R., Maqueda, M., Martínez-Férez, A., Segura-Carretero, A. and Robert, P. (2019). Evolution of the phenolic compounds profile of olive leaf extract encapsulated by spray-drying during in vitro gastrointestinal digestion. Food Chemistry, 279, $\quad 40-48 . \quad$ https://doi.org/10.1016/ j.foodchem.2018.11.127

Palma, M., García, P., Márquez-Ruiz, G., Vergara, C. and Robert, P. (2014). Release kinetics of flavonoids in methyl linoleate from microparticles designed with inulin and channelizing agent. Food Research International, 64, 99-105. https://doi.org/10.1016/ j.foodres.2014.05.064

Robert, P., García, P., Reyes, N., Chávez, J. and Santos, J. (2012). Acetylated starch and inulin as encapsulating agents of gallic acid and their release behaviour in a hydrophilic system. Food Chemistry, 134(1), $\quad 1-8 . \quad$ https://doi.org/10.1016/ j.foodchem.2012.02.019

Saénz, C., Tapia, S., Chávez, J. and Robert, P. (2009). Microencapsulation by spray drying of bioactive compounds from cactus pear (Opuntia ficus-indica). Food Chemistry, 114(2), 616-622. https:// doi.org/10.1016/j.foodchem.2008.09.095

Saloko, S., Darmadji, P., Setiaji, B., Pranoto, Y. and Anal, A.K. (2013). Encapsulation of coconut shell liquid smoke in chitosan-maltodextrin based nanoparticles. International Food Research Journal, 20(3), 1269-1276.

Saloko, Satrijo, Darmadji, P., Setiaji, B. and Pranoto, Y. (2014). Antioxidative and antimicrobial activities of liquid smoke nanocapsules using chitosan and maltodextrin and its application on tuna fish preservation. Food Bioscience, 7, 71-79. https:// doi.org/10.1016/j.fbio.2014.05.008
Silva-Ibrahim, P., Stringheta, P.C., Teofilo, R.F. and De Oliveira, I.R.N. (2013). Parameter optimization for spray-drying microencapsulation of jaboticaba (Myrciaria jaboticaba) peel extracts using simultaneous analysis of responses. Journal of Food Engineering, 117(4), 538-544. https:// doi.org/10.1016/j.jfoodeng.2012.08.039

Silva-Weiss, A., Bifani, V., Ihl, M., Sobral, P.J.A. and Gómez-Guillén, M.C. (2013). Structural properties of films and rheology of film-forming solutions based on chitosan and chitosan-starch blend enriched with murta leaf extract. Food Hydrocolloids, 31(2), 458-466.

https://doi.org/10.1016/

j.foodhyd.2012.11.028

Sun-Waterhouse, D., Wadhwa, S.S. and Waterhouse, G.I.N. (2013). Spray-Drying Microencapsulation of Polyphenol Bioactives: A Comparative Study Using Different Natural Fibre Polymers as Encapsulants. Food and Bioprocess Technology, 6(9), 2376-2388. https://doi.org/10.1007/s11947-012-0946-y

Tonon, R.V., Baroni, A.F., Brabet, C., Gibert, O., Pallet, D. And Hubinger, M.D. (2009). Water sorption and glass transition temperature of spray dried açai (Euterpe oleracea Mart.) juice. Journal of Food Engineering, 94(3-4), 215-221. https:// doi.org/10.1016/j.jfoodeng.2009.03.009

Tonon, R.V., Brabet, C. and Hubinger, M.D. (2010). Anthocyanin stability and antioxidant activity of spray-dried açai (Euterpe oleracea Mart.) juice produced with different carrier agents. Food Research International, 43(3), 907-914. https:// doi.org/10.1016/j.foodres.2009.12.013

Yousefi, S., Emam-Djomeh, Z., Mousavi, M., Kobarfard, F. and Zbicinski, I. (2015). Developing spray-dried powders containing anthocyanins of black raspberry juice encapsulated based on fenugreek gum. Advanced Powder Technology, 26(2), 462-469. https://doi.org/10.1016/j.apt.2014.11.019

Yudhistira, B., Abigail, L.E., Siswanti. and Prabawa, S. (2020). The effect of blanching and foam mat drying on the physico-chemical characteristics of white sweet potato (Ipomoea batatas L.) inulin. Food Research, 4(5), $1493-1499 . \quad \mathrm{https} / /$ doi.org/10.26656/fr.2017.4(5).416

Yudhistira, B., Siswanti and Luwidharto, J.C.N. (2020). The Effect of Solvent Ratio and Precipitation Time on Isolation of Inulin from White Sweet Potato (Ipomoea batatas L.). International Seminar on Agribusiness, 518, $012009 . \quad \mathrm{https}: / /$ doi.org/10.1088/1755-1315/518/1/012009 